\title{
RESEARCH ON MODEL FITTING AND STRENGTH CHARACTERISTICS OF CRITICAL STATE FOR EXPANSIVE SOIL
}

\author{
Zhiqing $\mathrm{Li}^{1}$, Chuan Tang ${ }^{2}$, Ruilin $\mathrm{Hu}^{3}$, Yingxin $\mathrm{Zhou}^{4}$ \\ ${ }^{1,3}$ Key Laboratory of Engineering Geomechanics, Institute of Geology and Geophysics, \\ Chinese Academy of Sciences, No. 19 Beituchengxilu, Chaoyang district, Beijing 100029, China \\ ${ }^{1,2}$ State Key Laboratory of Geohazard Prevention and Geoenvironment Protection, \\ Chengdu University of Technology, Chengdu 610059, China \\ ${ }^{1}$ State Key Laboratory for GeoMechanics and Deep Underground Engineering, \\ China University of Mining \& Technology, Xuzhou 221008, China \\ ${ }^{1}$ Key Laboratory of Geotechnical and Underground Engineering, Tongji University, \\ Ministry of Education, Shanghai 200092, China \\ ${ }^{1}$ State Key Laboratory of Simulation and Regulation of Water Cycle in River Basin, \\ China Institute of Water Resources and Hydropower Research, Beijing 100044, China \\ ${ }^{4}$ Yunnan Mengxin Highway Construction Headquarters, Kunming 650011, China \\ E-mails: ${ }^{1}$ lizhiq-2002@163.com (corresponding author); ${ }^{2}$ tang_chuan@163.com; \\ ${ }^{3}$ rlinhu@sohu.com; ${ }^{4} z y x i n @$ sohu.com \\ Received 28 Apr. 2011; accepted 08 Jun. 2011
}

\begin{abstract}
According to Mengzi expansive soil, consolidated drained tests and undrained tests are carried on under saturated and remoulded conditions. The stress-strain characteristics of saturated soil are researched systematically under different confining pressure, initial dry density, initial water content, shearing rate and drainage condition. The inherent unity of diversity of shearing strength for the same samples measured by different experimental methods is indicated according to the normalization of critical state test results. And the failure lines in $p^{\prime}-q-v$ space of remoulded saturated expansive soil under consolidated drained and undrained conditions are attained. The hyperbolic curve model can fit well the weak hardening stress-strain curves and the exponential curve model can fit the weak softening stress-strain curves. The test results can provide technical parameters and theoretical help for shearing strength variation of slope during rainfall and strength state of soil structure in normal water level.
\end{abstract}

Keywords: expansive soil, critical state, remoulded soil, normalization.

\section{Introduction}

Undrained strength indices are often used in analysis of strength and stability for the difficult in the determination of excess pore water pressure in practical engineering. Schofield (2006) suggested that the critical strength should be adopted for design basis. The $\mathrm{K}_{0}$ compression curves of normally consolidated soil and critical state lines can be simplified to be parallel lines in $e-\lg p^{\prime}$ coordinate system. Wood (1990) proposed that the stress ratio of critical state met certain relationships in triaxial compression and tension condition. Roscoe and Burland (1968) pointed out that there was a unique relationship, which did not change with stress path, among $p, q, e$ of normally consolidated clay and weak consolidated remoulded clay. Parry (1960) indicated that drained triaxial shearing test results going through different stress path under the same confining pressure would achieve the same critical state for normally consolidated soil and overconsolidated soil. Chen and Saleeb (2005) proposed that the shearing strength of samples with the same initial void ratio would tend to be uniform in undrained shearing tests. Liu et al. (2006) indicated that critical stated model was capable of simulating strain hardening, softening, normal dilatancy and stress-path dependency of interface between sandy soil and structures during shearing. The unified modeling of the behavior of interfaces with different roughness, different density of soil and different normal pressures using the concept of critical state soil mechanics is also successfully attempted. Gitau et al. (2006) applied critical state soil mechanics to study the stress-strain behaviour of the luvisols using triaxial tests under laboratory conditions. An exponential model used to fit the deviatoric stress-axial strain test data accurately predicted the soil shear strength at the critical states. Saffih-Hdadi et al. (2009) proposed that confined compression tests were performed on remoulded soils at different initial bulk densities and water contents. Good linear regression was obtained between soil precompression stress, the compression index, initial water content, initial bulk density and soil texture. Suebsuk et al. (2010) introduced a plastic potential to account for the influence of 
structure on the plastic strain direction for both hardening and softening behaviours. Muhunthan and Worthen (2011) pointed out that the shear strength and deformation behavior of soil was quite sensitive to the combination of changes in volume and confining stress.

Remoulded expansive soils in Mengzi area are used in consolidated drained tests (CD) and consolidated undrained tests to discuss the saturated strength characteristics. The stress-strain characteristics of saturated samples under different consolidated confining pressure $\sigma_{3}$, initial dry density $\rho_{d}$, initial water content $\omega_{0}$, shearing rate $v$ and drainage condition are researched and fitted. The test results can provide technical parameters and theoretical help for shearing strength variation of slope during rainfall and strength state of soil structure in normal water level.

\section{Test method}

Test apparatus is an automatic triaxial shearing apparatus which is produced by KTG company. The apparatus equips with programmable stepless variable speed control and stepping motor loading. Samples are selected at Mengzi County in Yunnan province. Qu et al. (2000) indicated that the expansive soil in the area belongs to eluvial class fissured clay. Mineral component of clay include montmorillonite, illite and kaolinite. The content of montmorillonite, which is higher, is about $22 \%$ to $48 \%$. The free swelling ratio of samples is about $30 \%$ to $60 \%$. The highest is up to $130 \%$. The physical and mechanical indices of samples are presented in Table 1.

The specific test method is as following: 1 - the expansive soil is weathered and grinded. The soil particles are filtered by geotechnical sieve with aperture of $2 \mathrm{~mm}$ diameter. Some water is added to reach certain water content and enclosed more than 48 hours; 2 - remoulded samples are prepared as diameter of $39.1 \mathrm{~mm}$ and $80 \mathrm{~mm}$ height. The demands of consolidated drained test are $20 \%$ of initial water content, $1.5 \mathrm{~g} / \mathrm{cm}^{3}$ of dry density, $0.012 \% / \mathrm{min}$ and $0.007 \% / \mathrm{min}$ of shearing rate. The demands of consolidated undrained test are $16 \%$ and $18 \%$ of initial water content, $1.5 \mathrm{~g} / \mathrm{cm}^{3}$ and $1.7 \mathrm{~g} / \mathrm{cm}^{3}$ of dry density, $0.1 \% / \mathrm{min}$ and $0.05 \% / \mathrm{min}$ of shearing rate. In Table 2, SS means shearing strain softening and SH means shearing strain hardening; 3 - samples are laid in vacuum chamber and pumped down to be saturated more than 6 hours. The saturated sample is put in KTG automatic triaxial shearing apparatus. When value $\mathrm{B}$ is equal or greater than 0.95 , it means the sample is saturated by back pressure. Then the drained of undrained test is carried on after the isotropic consolidation.

\section{Analysis of test results}

\subsection{Effect of confining pressure}

The relationship between stress and strain is presented in Fig. 1. The bigger the confining pressure is, the bigger the shearing strength is. The sample which has bigger shearing strength is easy to exhibit a kind of strain softening characteristic. The phase transition behavior from strain hardening to strain softening appears gradually with the confining pressure increasing. The phenomenon of shear dilatation occurs easier when the density of consolidated sample is larger and larger with consolidated pressure increasing. The topsoil is easy to collapse for the lower confining pressure and shear strength in slope of expansive soil.

\subsection{Effect of initial dry density}

It has great effect for initial dry density to stress-strain characteristics of samples under the same initial water content and shearing rate in CU tests. The steady state line of sample with the bigger initial dry density is underneath the line of sample with the smaller initial dry density in the relationship between average effective normal stress and specific volume in Fig. 2 . The two steady state lines of samples with different dry density show the parallel relationship. The bigger the initial dry density is, the bigger the shearing strength is. The stress-strain behaviors of samples change from strain hardening to strain softening with dry density increasing. It has great guiding significance for the change of failure mode in engineering practice of expansive soil.

\subsection{Effect of initial water content}

It has great effect for initial water content to stress-strain characteristics of samples under the same initial dry density and shearing rate in CU tests. The steady state line of

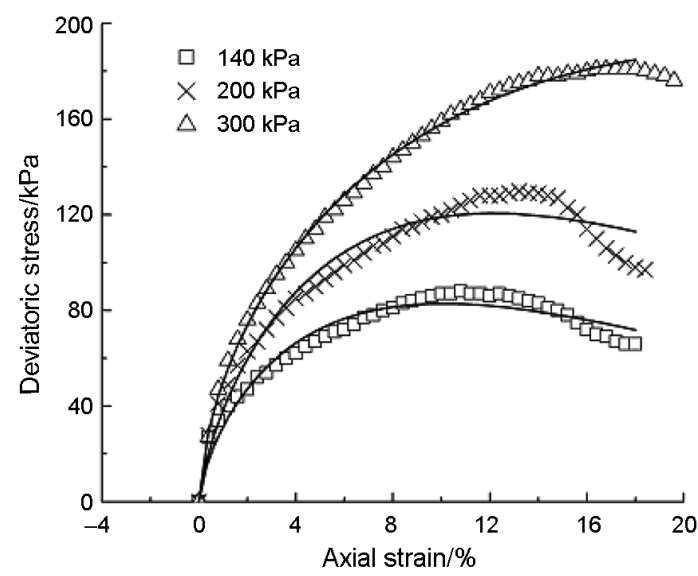

a) CD1

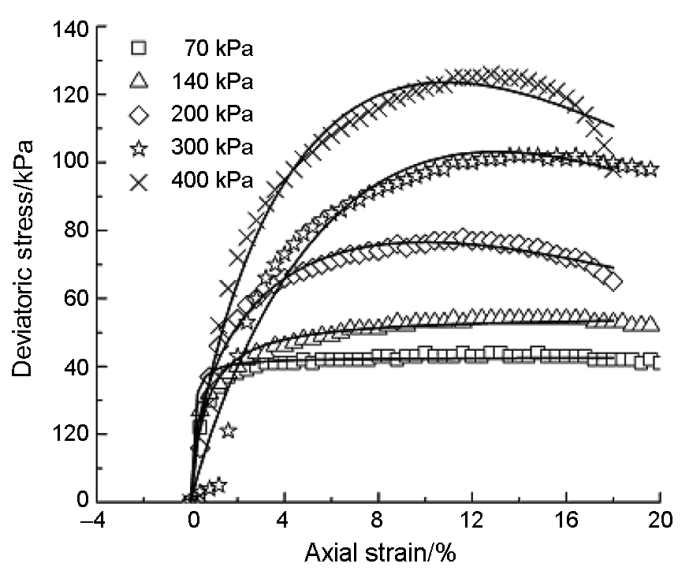

b) $\mathrm{CU} 2$

Fig. 1. Fitting stress-strain curves for partial samples 


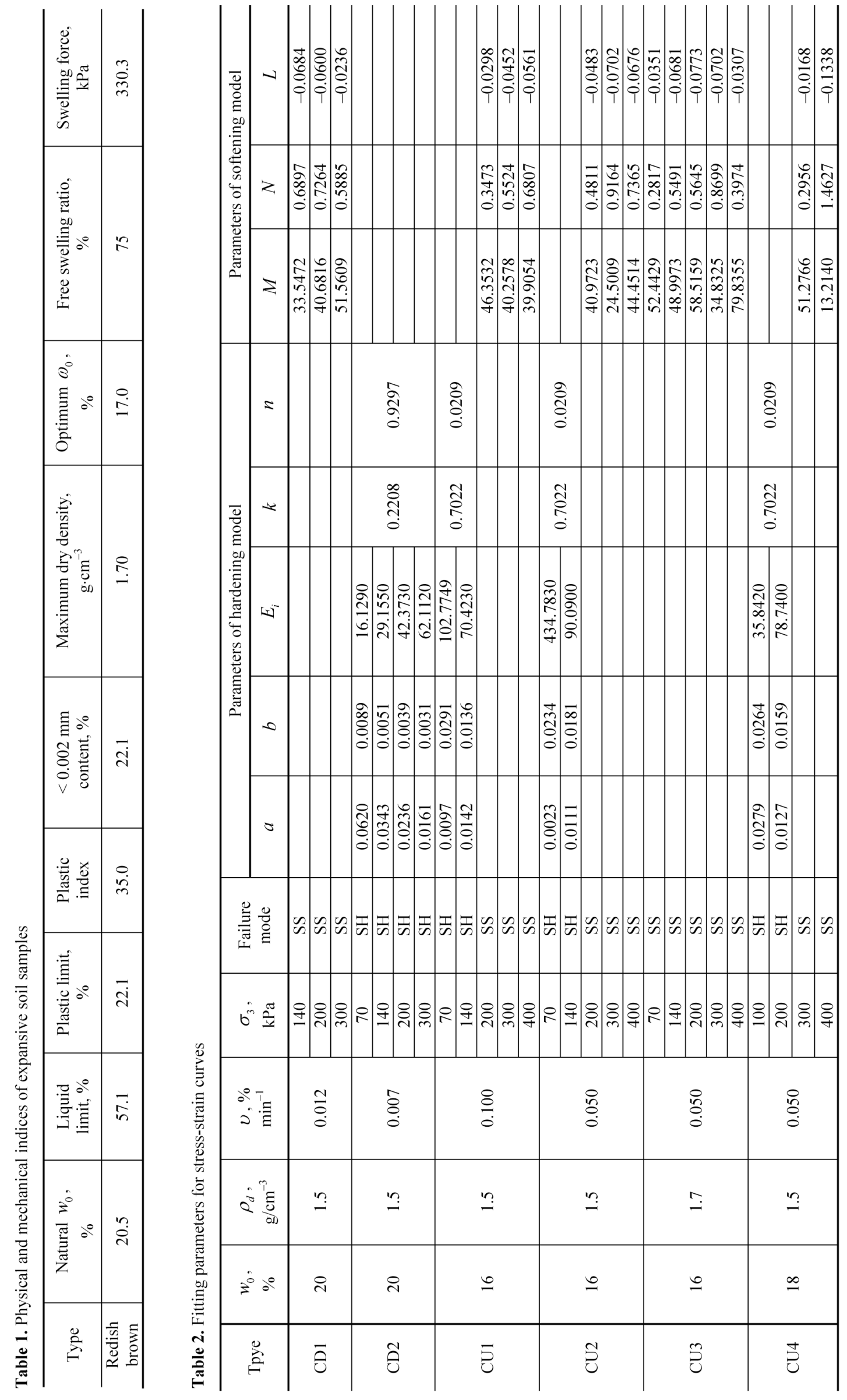


sample with the bigger initial water content is above the line of sample with the smaller initial water content in Fig. 2. The two steady state lines of samples with different water content show the parallel relationship. The lower the initial water content is, the bigger the shearing strength is.

\subsection{Effect of shearing rate}

It has great effect for shearing rate to stress-strain characteristics of samples under the same initial dry density and water content in $\mathrm{CU}$ and $\mathrm{CD}$ tests. The results are presented in Fig. $2 \mathrm{c}$ and $2 \mathrm{~d}$. The steady state line of sample with the bigger shearing rate is above the line of sample with the smaller shearing rate. The two steady state lines of samples with different shearing rate show the parallel relationship. The larger the shearing rate is, the larger the shear strength of sample is in CU test. The larger the shearing rate is, the smaller the shear strength of sample is in the CD test. The rule is just opposite for shearing drainage condition. The higher shearing rate causes strain softening phenomenon

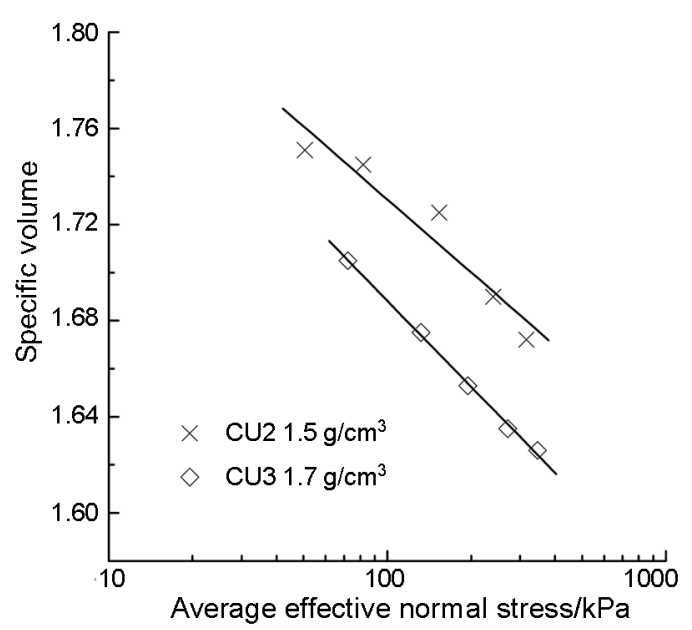

a) Different initial dry density

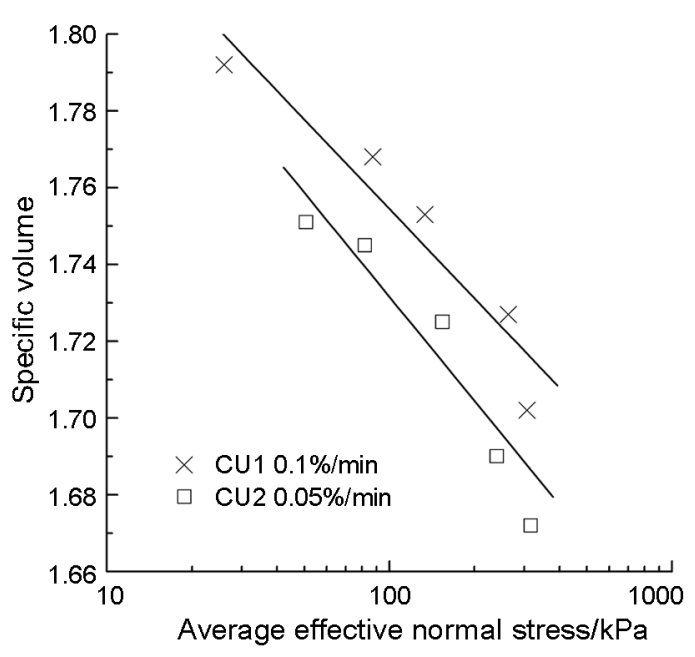

c) Different shearing rate for $\mathrm{CU}$ tests and the lower shearing rate causes strain hardening of sample. The phenomenon indicates that the bifurcation appears in shearing process. One is that the deformation of sample expands sequentially and tends to be hardening condition. The other is that shearing zone appears and tends to softening in macroscopic view. The long-axis direction of soil particle is gradually perpendicular to direction of maximum principal stress to increase the contract area inter particles in shearing process when the shearing rate is smaller. At the result, the hardening phenomenon behaves gradually. If all the particles achieve the oriented arrangement and hardening reaches a limit, the compressive deformation of sample will emerge uniformly. When shearing rate is bigger, the main deformation will be limited in shearing zone and the particles directionally arrange along shearing zone. The main reason is that there's not enough time for soil particles to make hardening arrangement. The oriented arrangement of particles often begins from the weak points inside the sample and then extends gradually through a shearing zone.

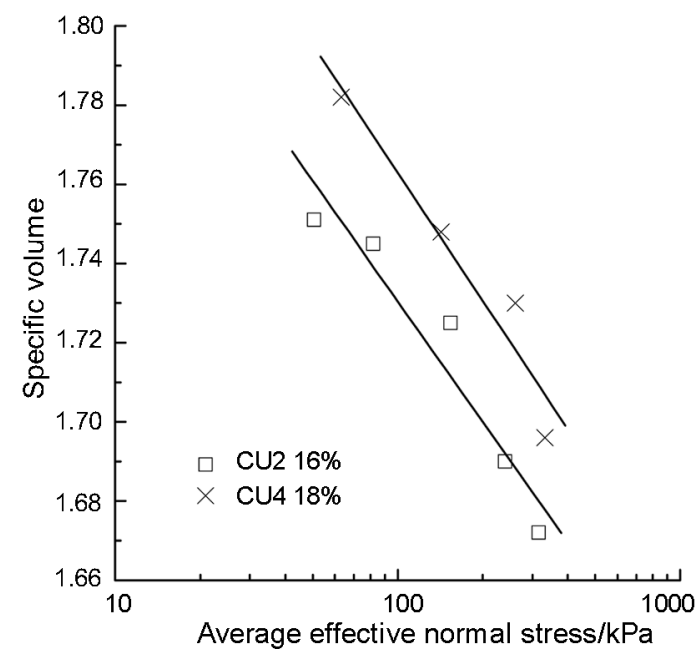

b) Different initial water content

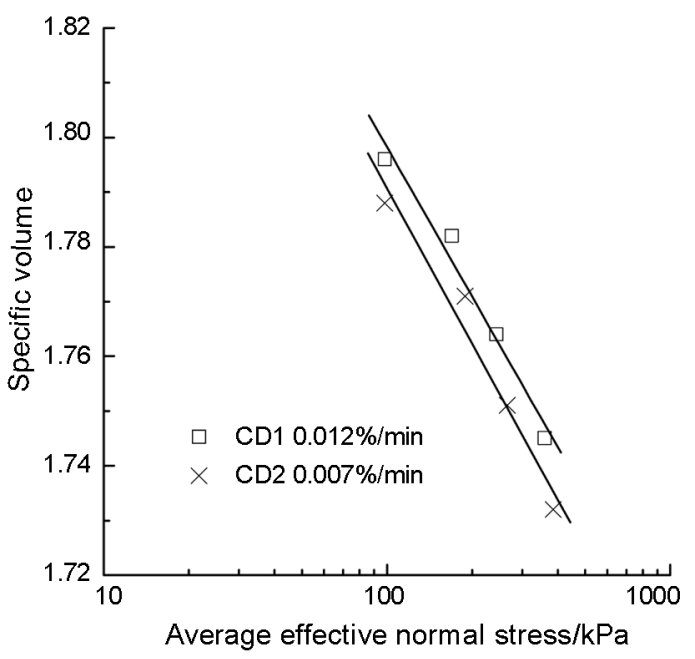

d) Different shearing rate for CD tests

Fig. 2. Relationship between average effective normal stress and specific volume under different parameters 


\subsection{Effect of drainage condition}

Alarcon-Guzman et al. (1988) indicated that it had different effect for different drainage conditions to steady state. Yamamuro and Lade (1998) found that the steady state line of silt under drainage condition and undrainage condition was the same line within the limit from $200 \mathrm{kPa}$ to $1000 \mathrm{kPa}$ confining pressure. The steady state line under drainage condition was still higher the line under undrainge condition below $200 \mathrm{kPa}$ pressure. Yang (2000) concluded that it had a certain effect to steady state for drainage condition of weathered granite and weathered volcanic in Hong Kong. The steady state line of sample under drainage condition which exhibits a higher steady state is above the line under undrainage condition in Fig. 3. The effect of drainage condition to triaxial shearing test exhibits mainly the influence of excess pore water pressure during shearing test. The stain hardening behavior is easier to appear under drainage condition than undrainage condition.

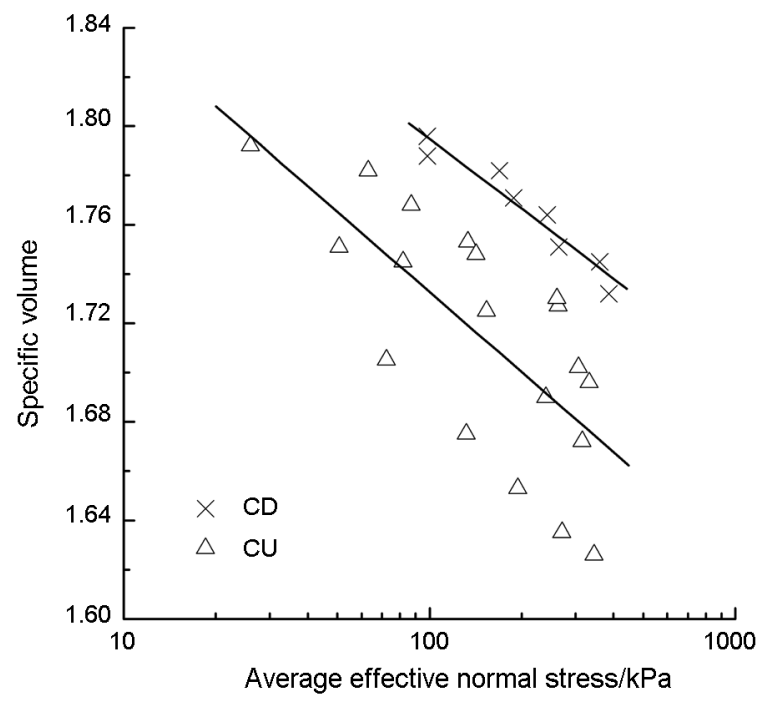

Fig. 3. Comparison between $p^{\prime}$ and $v$ under different drainage conditions

\subsection{Treatment of normalization}

Li et al. (2008) measured the mechanical strength of expansive soil by different test methods to attain the uniform rule. Different sample dimension and test methods will cause the differences in mechanical strength measuring of soil. The samples used in triaxial tests have three kinds of diameters: $39.1 \mathrm{~mm}, 50.0 \mathrm{~mm}$ and $61.8 \mathrm{~mm}$. The different sample dimension will cause different test results. It has great differences to compare shearing test results of indoor samples and big samples in field. The mechanical parameters tested by different apparatuses all have differences attributing to the differences of characteristics of shear plane and stress conditions. So the relationship between average effective normal stress and specific volume is not the only one. It depends on some factors such as initial water content, initial dry density, drainage condition, shearing rate, and so on. The normalization method can be used to achieve the unique relationship between average effective normal stress and specific volume. The initial dry density and water content are used to be normalization parameters in the same shearing rate condition as showed in Eq. (1). The linear relationship after normalization can be expressed by the formula $v=\Gamma-\lambda \ln p^{\prime}$ as showed in Fig. 4:

$$
e=e_{c} \rho_{n} \omega_{n}
$$

where: $\quad \rho_{n}=\rho_{0} / \rho_{o p}, \quad \omega_{n}=1+\frac{\omega_{o p}-\omega_{0}}{5 \omega_{o p}}, e$ is void ratio; $e_{c}$ is void ratio after consolidation; $\rho_{0}$ is initial dry density; $\rho_{o p}$ is the optimum dry density; $\rho_{o p}=$ $1.70 \mathrm{~g} / \mathrm{cm}^{3} ; \omega_{0}$ is initial water content; $\omega_{o p}$ is the optimum water content; $\omega_{o p}=17 \%$. The linear relationship is fitted by the formula: $v=1.7726-0.0389 \ln p^{\prime}$. Here: $v-$ specific volume; $p^{\prime}$ - average effective normal stress. The fitting parameters $\Gamma=1.7726 ; \lambda=0.0389$.

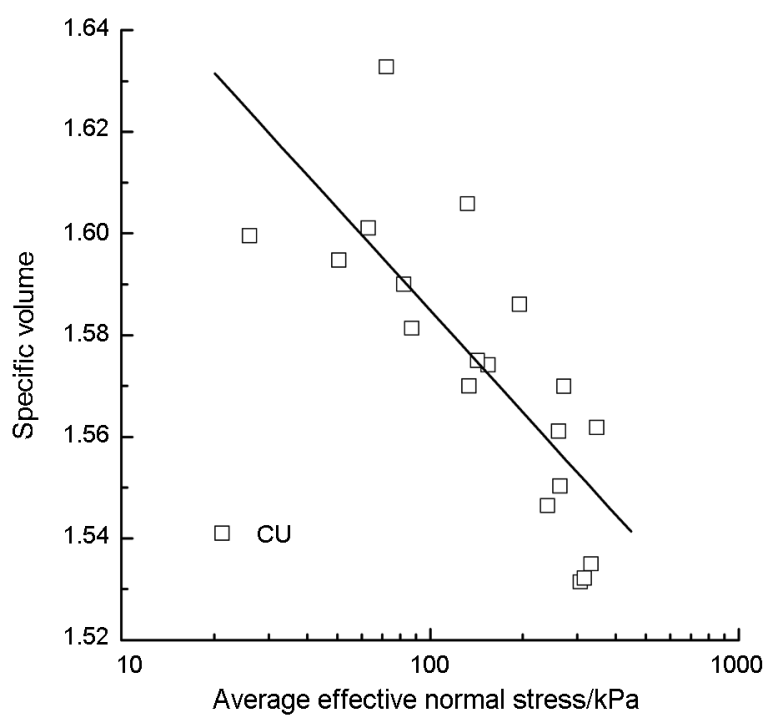

Fig. 4. Relationship between $p^{\prime}$ and $v$ after normalization

\section{Fitting of stress-strain model}

In CU tests, the stress-stain relationship of sample pertains to weak hardening when the consolidated pressure is smaller than $200 \mathrm{kPa}$. And the relationship pertains to weak softening when the pressure is bigger than $200 \mathrm{kPa}$. In $\mathrm{CD}$ tests, the stress-stain relationship of sample belongs to weak hardening when the shearing rate is smaller. And the relationship belongs to weak softening when the shearing rate is larger.

The hyperbolic model (2) can be used to simulate the weak hardening stress-strain relationship as showed in Fig. 1 and the fitting parameters are showed in Table 2:

$$
\begin{gathered}
q=\sigma_{1}-\sigma_{3}=\frac{\varepsilon_{a}}{a+b \varepsilon_{a}} ; \\
\frac{\varepsilon_{a}}{q}=a+b \varepsilon_{a},
\end{gathered}
$$


where: $q$ is deviatoric stress; $\sigma_{1}$ is major principal stress; $\sigma_{3}$ is minor principal stress; $\varepsilon_{a}$ is axial strain; $a$, $b$ are fitting parameters. They can be attained by stressstrain curves of conventional triaxial tests.

The tangent modulus $E_{t}$ is attained by derivation of $q$ with respect to $\varepsilon_{a}$ as showed in Eq. (3):

$$
E_{t}=\frac{d q}{d \varepsilon_{a}}=\frac{a}{\left(a+b \varepsilon_{a}\right)^{2}} .
$$

The young modulus:

$$
E_{i}=\left(\frac{d q}{d \varepsilon_{a}}\right)_{\varepsilon_{a} \rightarrow 0}=\frac{1}{a} .
$$

The peak deviatoric stress:

$$
q_{p}=q_{\varepsilon_{a} \rightarrow \infty}=\frac{1}{b} .
$$

The initial young modulus $E_{i}$ depends on initial confining pressure $\sigma_{3}$ and initial dry density $\rho_{d}$. Janbu (1963) suggested that initial young modulus could be expressed by the Eq. (6) considering void ratio:

$$
E_{i}=k P_{a}\left(\frac{p_{0}}{p_{a}}\right)^{n},
$$

where $k$ and $n$ are test parameters. They can be attained by the power function relationship between $\frac{E_{i}}{p_{a}}$ and $\frac{p_{0}}{p_{a}}$. $P_{a}$ is standard atmosphere.

Exponential model (7) can be used to simulate weak softening stress-strain curves as showed in Fig. 1. The fitting parameters are showed in Table 2:

$$
q=\sigma_{1}-\sigma_{3}=M \varepsilon_{a}^{N} e^{L \varepsilon_{a}} .
$$

The Eq. (8) is attained by taking logarithm of both sides of Eq. (7):

$$
\lg q=A+N \lg \varepsilon_{a}+B \varepsilon_{a}
$$

where: $A=\lg M, B=L \lg e, M, N, L, A, B$ are fitting parameters.

The tangent modulus $E_{t}$ is attained by derivation of Eq. (8) with respect to $\varepsilon_{a}$ as showed in Eq. (9):

$$
E_{t}=\frac{d q}{d \varepsilon_{a}}=q\left(\frac{N}{\varepsilon_{a}}+L\right) .
$$

Young modulus:

$$
E_{i}=\left(\frac{d q}{d \varepsilon_{a}}\right)_{\varepsilon_{a} \rightarrow 0}=\infty .
$$

\section{Conclusions}

According to Mengzi expansive soil, the saturated strength tests of consolidated drainage (CD) and undrainage (CU) are carried on. The mainly conclusions are as following:

1. The mechanical characteristics of Mengzi saturated soil are researched in CD and CU conditions by using theory of critical state. It has great influence for the factors: confining pressure, initial dry density, initial water content, shearing rate and drainage condition to the characteristics of stress-strain of soil.

2. The inherent unity of diversity of shearing strength for the same samples measured by different experimental methods is indicated according to the normalization of critical state test results. And the failure lines in $p^{\prime}-q-v$ space of remoulded saturated expansive soil under consolidated drained and undrained condition are attained.

3. Consolidated drained tests of saturated expansive soil present strain hardening regularity. And the tests have characteristics of shear dilatation. The hyperbolic curve model can fit well the weak hardening stress-strain curve. Consolidated undrained test of sample presents strain softening regularity. The exponential curve model can fit the weak softening stress-strain curves.

\section{Acknowledgements}

This research is financially supported by National Natural Science Foundation of China (NO. 41102186); Opening fund of State Key Laboratory of Geohazard Prevention and Geoenvironment Protection (Chengdu University of Technology) (SKLGP2011K001); Opening fund of State Key Laboratory for Geomechanics and Deep Underground Engineering (China University of Mining \& Technology) (SKLGDUEK 1006); Opening fund of Key Laboratory of Geotechnical and Underground Engineering (Tongji University), Ministry of Education(KLE-TJGE-B0903); the Open Research Fund of State Key Laboratory of Simulation and Regulation of Water Cycle in River Basin (China Institute of Water Resources and Hydropower Research), Grant NO: IWHR-SKL - 201217.

\section{References}

Alarcon-Guzman, A.; Leonards, G. A.; Chameau, J. L. 1988. Undrained monotonic and cyclic strength of sands, Journal of Geotechnical Engineering ASCE 114(10): 10891109. http://dx.doi.org/10.1061/(ASCE)0733-9410(1988) 114: 10(1089)

Chen, W. F.; Saleeb, A. F. 2005. Constitutive equations for concrete and soil. Beijing: China Architecture \& Building Press. $576 \mathrm{p}$.

Gitau, A. N.; Gumbe, L. O.; Biamah, E. K. 2006. Influence of soil water on stress-strain behaviour of a compacting soil in semi-arid Kenya, Soil and Tillage Research 89(2): 144154. http://dx.doi.org/10.1016/j.still.2005.07.008

Janbu, N. 1963. Soil compressibility as determined by oedometer and triaxial tests, in Proc. of the European Conference on Soil Mechanics and Foundation Engineering, vol. 1, 1963, Wiesbaden, 19-25. 
Li, Z.-Q.; Li, T.; Hu, R.-L.; Wang, L.-C.; Wang, Y.-P. 2008. Expansion characteristics and construction control of remoulded Mengzi expansive soil, Chinese Journal of Geotechnical Engineering 30(12): 1855-1860.

Liu, H.; Song, E.; Ling, H. I. 2006. Constitutive modeling of soil-structure interface through the concept of critical state soil mechanics, Mechanics Research Communications 33(4): 515-531. http://dx.doi.org/10.1016/j.mechrescom.2006.01.002

Muhunthan, B.; Worthen, D. L. 2011. Critical state framework for liquefaction of fine grained soils, Engineering Geology $117(1-2)$ : $2-11$.

http://dx.doi.org/10.1016/j.enggeo.2010.09.013

Parry, R. H. G. 1960. Triaxial compression and extension tests on remoulded saturated clay, Geotechnique 10(4): 166180. http://dx.doi.org/10.1680/geot.1960.10.4.166

Qu, Y. X.; Zhang, Y. S.; Yang, J. F., et al. 2000. Theory and practice of engineering geology classify of integration of expansive rock and soil of China, in S. J. Wang (Ed.). Fifty Years of Engineering Geology of China, Selected papers, vol. 1. Beijing: Seismic Publishing House, 148-253.

Roscoe, K. H.; Burland, J. B. 1968. On the generalized stressstrain behavior of "Wet" clay, in Heyman, J.; Leckie, F. A. (Eds.). Engineering Plasticity. England: Cambridge University Press, 535-609.
Saffih-Hdadi, K.; Défossez, P.; Richard, G.; Cui, Y.-J.; Chaplain, V. 2009. A method for predicting soil susceptibility to the compaction of surface layers as a function of water content and bulk density, Soil and Tillage Research 105(1): 96-103. http://dx.doi.org/10.1016/j.still.2009.05.012

Schofield, A. N. 2006. Interlocking and peak and design strengths, Geotechnique 56(5): 357-358. http://dx.doi.org/10.1680/geot.2006.56.5.357

Suebsuk, J.; Horpibulsuk, S.; Liu, M. D. 2010. Modified structured cam clay: A generalised critical state model for destructured, naturally structured and artificially structured clays, Computers and Geotechnics 37(7-8): 956-968. http://dx.doi.org/10.1016/j.compgeo.2010.08.002

Wood, D. M. 1990. Soil behavior and critical state soil mechanics. London: Cambridge University Press. 462 p.

Yamamuro, J. A.; Lade, P. V. 1998. Steady-state concepts and static liquefaction of silt sands, Journal of Geotechnical and Geoenvironmental Engineering ASCE 124(9): 868877. http://dx.doi.org/10.1061/(ASCE)1090-0241(1998) 124:9(868)

Yang, Z. 2000. Fundamental shear behavior of saturated loose fills of completely decomposed rocks. PhD thesis, Hong Kong: University of Hong Kong. 205 p.

Zhiqing LI. PhD, Associate Professor. Research area: unsaturated soil and special soil, ei expansive soil, loess, salty soil and so on.

Chuan TANG. PhD, Professor. Research area: rock-soil mechanics and geologic hazard.

Ruilin HU. PhD, Professor. Research area: unsaturated soil and special soil.

Yingxin ZHOU. PhD, Professor. Research area: unsaturated soil. 